\title{
HOMENAJE AL MAGISTRADO DOCTOR ENRIQUE GIL-BOTERO POR SU LEGADO INTERNACIONAL AL DERECHO DE LA RESPONSABILIDAD
}

\section{TRIBUTE TO MAGISTRATE ENRIQUE GIL- BOTERO FOR HIS INTERNATIONAL LEGACY TO THE LAW OF RESPONSIBILITY}

\author{
Natalia Bernal-Cano* \\ Fecha de recepción: 6 de octubre de 2014 \\ Fecha de aceptación: 30 de noviembre de 2014 \\ Disponible en línea: 30 de junio de 2015
}

\section{Para citar este artículo/To cite this article}

Bernal-Cano, Natalia, Homenaje al magistrado doctor Enrique Gil-Botero por su legado internacional al derecho de la responsabilidad, 130 Vniversitas, 347-364 (2015). http://dx.doi.org/10.11144/Javeriana.vj130.hmde

doi:10.11144/Javeriana.vj130.hmde

* Doctora de l'Université Paris I Panthéon-Sorbonne. Fundadora y directora del Centro Europeo de Investigaciones de Derecho Comparado (European Research Center of Comparative Law, ERCOCL). 
Tengo el honor de presentar a los jueces, académicos, juristas, abogados y estudiantes de Derecho la traducción al francés de la joya de la literatura jurídica La responsabilidad del poder público, escrita en español por el honorable consejero de Estado colombiano Enrique Gil-Botero.

Traduje, comenté y publiqué esta obra en Alemania con el sello editorial de mi centro de investigaciones de Derecho Comparado European Research Center of Comparative Law, como un sincero homenaje al autor por su calidad humana y sus ilustres aportes al derecho de la responsabilidad, tanto en la academia como en su labor jurisdiccional en calidad de magistrado de la sección tercera del Consejo de Estado de la República de Colombia.

El doctor Gil Botero, reconocido erudito y defensor de la reparación integral del daño causado a la persona y a sus bienes patrimoniales, ha dejado en el viejo continente uno de sus más grandes legados. Su obra tiene el mérito de atravesar los límites de la percepción clásica de la teoría general de la responsabilidad del Estado, gracias a sus estudios casuísticos fundamentados a profundidad con rigurosos análisis de la jurisprudencia administrativa nacional y de diferentes ordenamientos jurídicos desde una amplia perspectiva comparativa.

En mi experiencia académica en el ámbito del Derecho Comparado, no había tenido entre mis manos un estudio tan completo y tan brillante de la jurisprudencia administrativa. La traducción al francés de La responsabilidad del poder público comienza igualmente a ser admirada y reconocida en el ámbito internacional por los interesantes debates de los magistrados colombianos relacionados con la responsabilidad extracontractual del Estado. Estos debates son citados y complementados con una argumentación completa y exhaustiva que el autor pone en evidencia para demostrar los sabios criterios que muchas veces adopta en sus salvamentos de voto.

La obra está compuesta por amplias secciones que desarrollan minuciosamente los temas de las formas de atribución de la responsabilidad, la clasificación de los daños antijurídicos y los sistemas de indemnización, principalmente en materia del ejercicio de la función pública, los servicios médicos y hospitalarios, los actos terroristas, los servicios públicos, el transporte y el enriquecimiento sin justa causa. Podemos percibir en cada una de estas secciones el 
espíritu de un juez activista y creativo que no se limita a la aplicación e interpretación del derecho, sino que garantiza su creación prudente y razonable para fortalecer la protección de los derechos y garantías individuales.

El derecho de la responsabilidad del Estado evoluciona a medida que, paralelamente, evolucionan los mecanismos de protección y reconocimiento de los derechos humanos como derechos constitucionales internacionales. Sin duda alguna, este proceso dinámico propio de una verdadera constitución viviente y ejemplarmente efectiva requiere aportes intelectuales innovadores que procuren el amparo eficaz y real de la persona afectada directamente por el Estado. La obra del doctor Gil-Botero no es un estudio filosófico alejado de la práctica ni de las necesidades de reparación; tampoco es un estudio de sistemas jurídicos aislados. Hablamos de un Tratado que analiza todo tipo de daño causado por el Estado desde su génesis hasta su resarcimiento integral y efectivo, no solo en Colombia sino en otros ordenamientos jurídicos. Con esta publicación, no solo se va a evitar en la práctica la obstrucción de la justicia administrativa por la radicación de múltiples demandas judiciales infundadas que se pueden instaurar como fuente de enriquecimiento patrimonial por daños inciertos o exageradamente valorados desde el punto de vista pecuniario, sino que se va a garantizar a la víctima de un daño injustificadamente causado por el Estado que sus defensores y jueces administrativos desarrollen argumentaciones sólidas, razonables y contundentes para probar y fundamentar jurídicamente las pretensiones dirigidas a obtener la correspondiente indemnización equilibrada de perjuicios conforme a los hechos demostrados en los procesos.

La versión francesa de la obra del doctor Gil-Botero permite que en los países francófonos y en otros horizontes se reconozca nuestra jurisprudencia, no solo para identificar los aportes de otros sistemas jurídicos a nuestro derecho interno sino para aportar a las jurisdicciones foráneas nuevos argumentos que hasta el momento no han sido plenamente desarrollados por estas últimas a la hora de declarar una reparación directa.

El derecho de la responsabilidad extracontractual del Estado hoy va más allá de la simple reparación de perjuicios estimados en un caso concreto y se convierte en un instrumento con efectos generales 
para prevenir los daños indemnizables y restaurar los derechos fundamentales vulnerados por el Estado en circunstancias semejantes. Lo anterior se demuestra en la fuerza obligatoria que tiene no solo la parte resolutiva de las decisiones del juez administrativo, sino su parte motiva, la cual se enriquece gracias a las fuentes formales y materiales del razonamiento judicial para constituir un precedente.

El precedente administrativo - al igual que el precedente constitucional — no solo se caracteriza por la creatividad, razonabilidad, consistencia, precisión y obligatoriedad de los argumentos esenciales que conforman la decisión judicial sino por su alcance general. Conforme a lo anterior, un argumento judicial de esta naturaleza solo puede reiterarse con eficacia si se encuentra enriquecido con debates doctrinales y detallados análisis jurisprudenciales como los que encontramos en la obra que tengo el honor de comentar.

La protección que ofrece el derecho de la responsabilidad del Estado es cada vez más integral y eficaz, gracias a la influencia que el derecho constitucional y el derecho comunitario ejercen en los sistemas jurídicos y en el orden objetivo de valores.

La obra del doctor Gil-Botero nos muestra que el debido proceso administrativo no es solamente un conjunto de garantías procesales constitucionales, sino un mecanismo de protección efectiva de los derechos fundamentales que resulten vulnerados por la actividad o las omisiones administrativas del Estado. Esta protección se garantiza gracias a la interpretación judicial global, sistemática y dinámica de los principios constitucionales explícitos e implícitos y a la aplicación de los tratados sobre derechos humanos en el derecho interno. En este sentido, el autor desarrolla el tema de los fundamentos constitucionales de la responsabilidad.

La problemática central del tratado es, entonces, el rol del juez administrativo en la protección de los derechos y libertades desde el punto de vista de la responsabilidad. Al respecto, vale la pena citar el siguiente ejemplo: el doctor Enrique Gil-Botero aborda entre otros temas, la responsabilidad del Estado en el marco del transporte terrestre y demuestra un aspecto muy interesante lejos de ser analizado por la doctrina tradicional. Se trata del desarrollo de la doctrina de los derechos universales derivados de la actividad del transporte terrestre. En este tema, el autor hace alusión al uso del espacio público y a la seguridad en las vías públicas. Este ejemplo 
de creación del derecho por medio de la jurisprudencia al igual que otros, complementa sin duda alguna aquello que está previsto en los códigos y tiene qué ver con la relación cada vez más directa e inmediata del juez con el administrado.

La obra suministra igualmente nuevos aportes que enriquecen la doctrina de los regímenes especiales de responsabilidad. El estudio se profundiza igualmente teniendo como referencia otros ordenamientos jurídicos como el francés. En ese sistema jurídico hay abundante jurisprudencia del Consejo de Estado relacionada con la responsabilidad del Estado por enfermedades nosocomiales e iatrogénicas, al igual que por transfusiones sanguíneas realizadas en los hospitales públicos. Esta amplia jurisprudencia desarrolla los regímenes especiales de responsabilidad en estos casos precisamente detallados y regulados en la Ley del 4 de marzo de 2002 sobre los derechos de los enfermos. A pesar de que legalmente el ordenamiento jurídico colombiano no dispone de una regulación específica y exclusiva para estos casos, hay igualmente una amplia jurisprudencia que es común a la francesa en lo relativo a la responsabilidad hospitalaria como institución jurídica y concepto genérico. Al respecto, vale la pena citar innumerables sentencias del Consejo de Estado colombiano que demuestran este tipo de responsabilidad a partir de una perspectiva global que abarca todo tipo de actividad hospitalaria.

Por otra parte, el ordenamiento jurídico francés muestra un interesante régimen particular de responsabilidad que, a pesar de que no se explica como tal en la obra, se encuentra implícitamente incorporado en los deberes de seguridad y protección del orden público que corresponden al Estado, los cuales son ampliamente explicados por el autor. Hablamos en este caso específico del "régimen de daños ocasionados en manifestaciones públicas" (Código General de Entidades Territoriales, L 2216-3 CGCT). En lo relacionado con estos regímenes particulares de responsabilidad regulados en Francia, también podemos citar el régimen específico de daños causados por los funcionarios públicos que desempeñan funciones docentes (Ley del 5 de abril de 1937), el régimen de los daños causados específicamente por los parlamentarios (ordenanza del 17 de noviembre de 1958), el régimen específico de los perjuicios ocasionados por enfermedades nocosomiales, iatrogénicas, por 
la vacunación, en lo relacionado con la responsabilidad médica (artículo L3111-9 del Código de Salud Pública). También podemos citar la indemnización de las personas afectadas por el contagio del sida con ocasión de una transfusión (Ley del 31 de diciembre de 1991), la indemnización de los daños causados por atentados terroristas (Ley del 9 de septiembre de 1986), la cual es ampliamente explicada por el autor en un capítulo de la obra.

Con esta reseña, procuro expresar mi sincera gratitud al doctor Gil-Botero por este maravilloso aporte que no solo se difundirá en la academia internacional, sino que sin duda alguna será un instrumento de valiosa ayuda en el desarrollo de los razonamientos judiciales. 


\section{BIBLIOGRAFÍA}

\section{Libros}

Alonso-García, Enrique, La interpretación de la Constitución (Centro de Estudios Constitucionales, CEC, Madrid, 1984).

Ballesteros-Garrido, José Antonio, Las condiciones generales de los contratos y el principio de autonomía de la voluntad (J. M. Bosch Barcelona, 1999).

Betancur-Jaramillo, Carlos, Derecho procesal administrativo (Señal Editora, Medellín, 1992).

Brichetti, Giovanni, La evidencia en el derecho procesal penal (Santiago SentísMelendo, trad., Ediciones Jurídicas Europa-América, Buenos Aires, 1973).

Cabanellas, Guillermo, Diccionario enciclopédico de derecho usual, tomo I (Editorial Heliasta, Buenos Aires, 1989).

Coviello, Pedro José Jorge, La protección de la confianza del administrado: derecho argentino y derecho comparado (Abeledo-Perrot, Buenos Aires, 2004).

Cuétara-Martínez, Juan Miguel de la, La actividad de la administración: lecciones de derecho administrativo (Tecnos, Madrid, 1983).

Díez-Picazo, Luis María, Sistema de derechos fundamentales ( $2^{\mathrm{a}}$ ed., Thomson-Civitas, Pamplona, 2005).

ESCRICHE, JOAQUín, Diccionario razonado de legislación y jurisprudencia, tomo IV (JUAN B. Guim, corrección y aumento, Editorial Temis, Bogotá, 1977).

Franco de Mora, Alicia \& Mora-Guevara, Nelson, Accidente automoviliario (2 $2^{\mathrm{a}}$ ed., Editorial Temis, Bogotá, 1977).

Fuster-Fabra Torrellas, José María, Responsabilidad civil derivada de actos de terrorismo (Atelier, Barcelona, 2001).

García de Enterría, Eduardo \& Fernández, Tomás-Ramón, Curso de derecho administrativo, tomo II ( $6^{\mathrm{a}}$ ed., Civitas, Madrid, 1999).

Gázquez-Serrano, Laura, La indemnización por causa de muerte (Dykinson, Madrid, 2000).

Garrido-Falla, Fernando, Tratado de derecho administrativo, vol. II ( $9^{\mathrm{a}}$ ed., Tecnos, Madrid, 1989).

Gil-Botero, Enrique, La responsabilidad del poder público (La responsabilité de la puissance publique). Chapitre préliminaire et traduction de l'espagnol vers le français de Natalia Bernal-Cano. Prólogo de Juan Carlos Henao y Ricardo de Ángel Yágüez (European Research Center of Comparative Law, Germany, 2014).

Gil-Botero, Enrique, Temas de responsabilidad extracontractual del Estado (3 ${ }^{\mathrm{a}}$ ed., Librería Jurídica Comlibros, Medellín, 2006).

Kaufmann, Arthur, Filosofía del derecho (traducción de la $2^{\mathrm{a}}$ ed., Universidad Externado de Colombia, Bogotá, 1999).

Larenz, Karl, Derecho justo. Fundamento de ética jurídica (Cuadernos Civitas S.A., Madrid, 1985). 
Leguina-Villa, Jesús, La responsabilidad civil de la administración pública (Tecnos, Madrid, 1983).

López-Garrido, Diego, Terrorismo, politica y derecho, La legislación antiterrorista en España, Reino Unido, República Federal de Alemania, Italia y Francia (Alianza Editorial, Madrid, 1987).

Mans-Puigarnau, Jaime M., Los principios generales del derecho (Bosch Casa Editorial, Barcelona, 1957).

Moreno-Martínez, Juan Antonio, coord., Perfiles de la responsabilidad civil en el nuevo milenio (Dykinson, Madrid, 2000).

Mosset-Iturraspe, Jorge \& Piedecasas, Miguel A., Responsabilidad precontractual (Rubinzal-Culzoni, Buenos Aires, 2006).

Murcia-Ballén, Humberto, Recurso de casación civil ( $3^{\mathrm{a}}$ ed., Librería El Foro de la Justicia, Bogotá, 1983).

Nieto-García, Alejandro, Derecho administrativo sancionador ( $2^{\mathrm{a}}$ ed., Tecnos, Madrid, 1994).

Olano-Valderrama, Carlos Alberto, Tratado técnico jurídico sobre accidentes de circulación y materias afines (Editorial Andes, Bogotá, 1975).

Ospina-Fernández, Guillermo, Régimen general de las obligaciones (Editorial Temis, Bogotá, 1998).

Peláez-Gutiérrez, Juan Carlos, Reflexiones sobre los fundamentos de la jurisprudencia administrativa francesa y colombiana en materia de actos de terrorismo (Universidad Externado de Colombia, Bogotá, 2000).

Pizarro, Ramón Daniel, Daño moral (Hammurabi, Buenos Aires, 1996).

RAPOPORT, DAvid C., La moral del terrorismo (Barcelona, Ariel, 1985).

Rawls, John, Liberalismo politico (Fondo de Cultura Económica, FCE, Bogotá, 1996).

Reyes-Alvarado, Yesid, Imputación objetiva (2ª ed., Editorial Temis, Bogotá, 1996).

Reyes-Echandía, Alfonso, La culpabilidad (Universidad Externado de Colombia, Bogotá, 1977).

Ripert, Georges \& Boulanger, Jean, Tratado de derecho civil, tomo III (Editorial La Ley, Buenos Aires, 1979).

Rodríguez-Rodríguez, Gustavo Humberto, Curso de derecho probatorio (Ediciones Librería del Profesional, Bogotá, 1990).

Rozo-Sordini, Paolo Emanuele, El daño biológico (Universidad Externado de Colombia, Bogotá, 2002).

Sayagués-Laso, Enrique, Tratado de derecho administrativo, tomo I (6 $6^{\mathrm{a}}$ ed., Facultad de Derecho y Ciencias Sociales, Fundación de Cultura Universitaria, Montevideo, 1988).

Velásquez-Velásquez, Fernando, Manual de derecho penal, parte general (2a ed., Editorial Temis, Bogotá, 2004). 


\section{Contribuciones en obras colectivas}

Busnelli, Francesco Donato, Problemas de la clasificación sistemática del daño a la persona, en Daños, 35-52 (Ramón Daniel Pizarro, Depalma, Buenos Aires, 1991).

Hoya-Coromina, José, La valoración del daño corporal, en Perfiles de la responsabilidad civil en el nuevo milenio, 253-258 (JuAn Antonio Moreno-Martínez, coord., Madrid, Dykinson (2000).

Pizarro-Leongómez, Eduardo, Terrorismo y democracia. El caso de Colombia, en Terrorismo y seguridad (Reinaldo Botero-Bedoya \& Malcom Deas, eds., Planeta, Bogotá, 2003).

\section{Revistas}

Fernández-Sessarego, Carlos, El daño a la persona, Revista de la Facultad de Derecho de la Pontificia Universidad Católica del Perú (1995).

Puy-Muñoz, Francisco, Sobre los principios generales del derecho, 37 Bilbao, Revista Estudios de Deusto, 83, 441-462 (1989).

Quintero-Navas, Gustavo, Conflicto armado y responsabilidad del Estado: análisis del derecho colombiano a la luz del derecho francés, 10 Revista de Derecho Público, Universidad de los Andes, 161-183 (1999).

\section{Legislación internacional}

Francia, Código de Salud Pública (Code de la santé publique). Disponible en: http:// legifrance.gouv.fr/affichCode.do?cidTexte=LEGITEXT000006072665\&dateTe $\mathrm{xte}=20150608$

Francia, Código General de Entidades Territoriales (Code général des collectivités territoriales, CGCT), Disponible en: http://www.legifrance.gouv.fr/ affichCodeArticle.do?cidTexte=LEGITEXT000006070633\&idArticle=LEGIA RTI000006390240\&dateTexte $=20130720$

Francia, Ley 86-1020 (Loi 86-1020, du 9 septembre 1986, relative à la lutte contre le terrorisme). Disponible en: http://legifrance.gouv.fr/affichTexte.do?cidTexte=J ORFTEXT000000693912

Francia, Ley 91-1406 (LOI no 91-1406, du 31 décembre 1991, portant diverses dispositions d'ordre social). Disponible en: http://www.legifrance.gouv.fr/affichTexte.do?cid Texte=JORFTEXT000000721455\&dateTexte $=19920104$

Francia, Ley 2002-303, de 4 de marzo, relativa a los derechos de los enfermos y a la calidad del sistema sanitario (Loi 2002-303, du 4 mars 2002, relative aux droits des malades et à la qualité du système de santé), Journal Officiel de la République Française, 5 de mars de 2002. Disponible en: http://www.legifrance.gouv.fr/ affichTexte.do?cidTexte=JORFTEXT000000227015

Francia, Loi de 5 avril 1937. 


\section{Jurisprudencia colombiana}

Año XLI, tomos LXX y LXXI, números 409-412, 1966, $2^{\mathrm{a}}$ parte, p. 830, sentencia de 22 de septiembre de 1966.

Consejo de Estado, Sección Tercera, auto de 8 de abril de 1994.

Consejo de Estado, Sección Tercera, expediente 14460, aclaraciones de voto de 18 de enero de 2008 a la sentencia de 3 de diciembre de 2007, providencia de 7 de abril de 2008.

Consejo de Estado, Sección Tercera, expediente 33584, aclaración de voto de 17 de junio de 2008 al auto de 21 de mayo de 2008.

Consejo de Estado, Sección Tercera, expediente 28106, auto de 18 de julio de 2007.

Consejo de Estado, Sección Tercera, expediente 33924, auto de 3 de septiembre de 2008.

Consejo de Estado, Sección Tercera, expediente 34228, auto de 3 de diciembre de 2008.

Consejo de Estado, Sección Tercera, expediente 35722, auto de 3 de diciembre de 2008.

Consejo de Estado, Sección Tercera, expediente 6607, sentencia de 11 de noviembre de 1986.

Consejo de Estado, Sección Tercera, expediente 3886, sentencia de 6 de agosto de 1987.

Consejo de Estado, Sección Tercera, expediente 4655, sentencia de 20 de febrero de 1989.

Consejo de Estado, Sección Tercera, expediente 5424, sentencia de 30 de noviembre de 1989.

Consejo de Estado, Sección Tercera, expediente 3510, sentencia de 30 de marzo de 1990, consejero ponente Luis Alberto Cifuentes-Lindarte. Disponible en: http://190.24.134.114:8080/WebRelatoria/ce/index.xhtml

Consejo de Estado, Sección Tercera, expediente 5417, sentencia de 11 de diciembre de 1990, consejero ponente Carlos Betancur-Jaramillo. Disponible en: http://190.24.134.114:8080/WebRelatoria/ce/index.xhtml

Consejo de Estado, Sección Tercera, expediente 5618, sentencia de 22 de febrero de 1991, consejero ponente Carlos Betancur-Jaramillo. Disponible en: http://190.24.134.114:8080/WebRelatoria/ce/index.xhtml

Consejo de Estado, Sección Tercera, expediente 6472, sentencia de 24 de octubre de 1991.

Consejo de Estado, Sección Tercera, expediente 6304, sentencia de 25 de octubre de 1991.

Consejo de Estado, Sección Tercera, expediente 6251, sentencia de 7 de noviembre de 1991, consejero ponente Julio César Uribe-Acosta. Disponible en: http://190.24.134.114:8080/WebRelatoria/ce/index.xhtml

Consejo de Estado, Sección Tercera, expediente 6431, sentencia de 21 de noviembre de 1991.

Consejo de Estado, Sección Tercera, expediente 6754, sentencia de 30 de julio de 1992.

Consejo de Estado, Sección Tercera, expediente 7428, sentencia de 6 de mayo de 1993, consejero ponente Julio César Uribe-Acosta. Disponible en: http://190.24.134.114:8080/WebRelatoria/ce/index.xhtml 
Consejo de Estado, Sección Tercera, expediente 7772, sentencia de 1 de julio de 1993, consejero ponente Daniel Suárez-Hernández. Disponible en: http://190.24.134.114:8080/WebRelatoria/ce/index.xhtml

Consejo de Estado, Sección Tercera, expediente 7622, sentencia de 12 de julio de 1993, consejero ponente Carlos Betancur-Jaramillo. Disponible en: http://190.24.134.114:8080/WebRelatoria/ce/index.xhtml

Consejo de Estado, Sección Tercera, expediente 8233, sentencia de 12 de noviembre de 1993, consejero ponente Daniel Suárez-Hernández. Disponible en: http://190.24.134.114:8080/WebRelatoria/ce/index.xhtml

Consejo de Estado, Sección Tercera, expediente 7818, sentencia de 9 de diciembre de 1993, consejero ponente Carlos Betancur-Jaramillo. Disponible en: http://190.24.134.114:8080/WebRelatoria/ce/index.xhtml

Consejo de Estado, Sección Tercera, expediente 8512, sentencia de 14 de diciembre de 1993, consejero ponente Daniel Suárez-Hernández. Disponible en: http://190.24.134.114:8080/WebRelatoria/ce/index.xhtml

Consejo de Estado, Sección Tercera, expediente 7756, sentencia de 21 de febrero de 1994.

Consejo de Estado, Sección Tercera, expediente 7973, sentencia de 18 de abril de 1994, consejero ponente Julio César Uribe-Acosta. Disponible en: http://190.24.134.114:8080/WebRelatoria/ce/index.xhtml

Consejo de Estado, Sección Tercera, expediente 8940, sentencia de 24 de junio de 1994.

Consejo de Estado, Sección Tercera, expediente 8577, sentencia de 23 de septiembre de 1994, consejero ponente Julio César Uribe-Acosta. Disponible en: http://190.24.134.114:8080/WebRelatoria/ce/index.xhtml

Consejo de Estado, Sección Tercera, expediente 9142, sentencia de 3 de febrero de 1995, consejero ponente Carlos Betancur-Jaramillo. Disponible en: http://190.24.134.114:8080/WebRelatoria/ce/index.xhtml

Consejo de Estado, Sección Tercera, expediente 11309, sentencia de 5 de marzo de 1995

Consejo de Estado, Sección Tercera, expediente 8118, sentencia de 8 de mayo de 1995, consejero ponente Juan de Dios Montes-Hernández. Disponible en: http://190.24.134.114:8080/WebRelatoria/ce/index.xhtml

Consejo de Estado, Sección Tercera, expediente 8305, sentencia de 24 de julio de 1995.

Consejo de Estado, Sección Tercera, expediente 10230, sentencia de 18 de abril de 1996.

Consejo de Estado, Sección Tercera, expediente 10627, sentencia de 13 de mayo de 1996.

Consejo de Estado, Sección Tercera, expediente 10461, sentencia de 5 de septiembre de 1996.

Consejo de Estado, Sección Tercera, expediente 11300, sentencia de 22 de octubre de 1997.

Consejo de Estado, Sección Tercera, expediente 11167, sentencia de 6 de noviembre de 1997, consejero ponente Carlos Betancur-Jaramillo. Disponible en: http://190.24.134.114:8080/WebRelatoria/ce/index.xhtml

Consejo de Estado, Sección Tercera, expediente 11837, sentencia de 8 de mayo de 1998, consejero ponente Jesús María Carrillo-Ballesteros. Disponible en: http://190.24.134.114:8080/WebRelatoria/ce/index.xhtml 
Consejo de Estado, Sección Tercera, expediente 10871, sentencia de 24 de septiembre de 1998, consejero ponente Juan de Dios Montes-Hernández, aclaración de voto de Ricardo Hoyos-Duque.

Consejo de Estado, Sección Tercera, expediente 10865, sentencia de 31 de agosto de 1999, consejero ponente Ricardo Hoyos-Duque. Disponible en: http://190.24.134.114:8080/WebRelatoria/ce/index.xhtml

Consejo de Estado, Sección Tercera, expediente 10755, sentencia de 26 septiembre 1999.

Consejo de Estado, Sección Tercera, expediente 11518, sentencia de 7 de octubre de 1999.

Consejo de Estado, Sección Tercera, expediente 11841, sentencia de 18 de mayo de 2000, consejero ponente Jesús María Carrillo-Ballesteros. Disponible en: http://190.24.134.114:8080/WebRelatoria/ce/index.xhtml

Consejo de Estado, Sección Tercera, expediente 12550, sentencia de 25 de mayo de 2000, consejero ponente Jesús María Carrillo-Ballesteros. Disponible en: http://190.24.134.114:8080/WebRelatoria/ce/index.xhtml

Consejo de Estado, Sección Tercera, expediente 11842, sentencia de 19 de julio de 2000, consejero ponente Alier Eduardo Hernández-Enríquez. Disponible en: http:// alizee.uniandes.edu.co/ava/AVA_200610_Derecho_Hipertexto/lib/exe/fetch. php?media=19_de_julio_de_2000.pdf

Consejo de Estado, Sección Tercera, expediente 11585, sentencia de 10 de agosto de 2000, consejero ponente Alier Eduardo Hernández-Enríquez. Disponible en: http://190.24.134.114:8080/WebRelatoria/ce/index.xhtml

Consejo de Estado, Sección Tercera, expediente 13386, sentencia de 14 de febrero de 2002, consejero ponente María Elena Giraldo-Gómez. Disponible en: http://190.24.134.114:8080/WebRelatoria/ce/index.xhtml

Consejo de Estado, Sección Tercera, expediente 13227, sentencia de 11 de abril de 2002, magistrado ponente Alier Eduardo Hernández-Enríquez. Disponible en: http://190.24.134.114:8080/WebRelatoria/ce/index.xhtml

Consejo de Estado, Sección Tercera, expediente 13234, sentencia de 2 de mayo de 2002, consejero ponente Germán Rodríguez-Villamizar. Disponible en: http://190.24.134.114:8080/WebRelatoria/ce/index.xhtml

Consejo de Estado, Sección Tercera, expediente 14211, sentencia de 23 de octubre de 2003, consejero ponente Ramiro Saavedra-Becerra. Disponible en: http://190.24.134.114:8080/WebRelatoria/ce/index.xhtml

Consejo de Estado, Sección Tercera, expediente 12916, sentencia de 11 de diciembre de 2003, consejero ponente Ricardo Hoyos-Duque. Disponible en: http://190.24.134.114:8080/WebRelatoria/ce/index.xhtml

Consejo de Estado, Sección Tercera, expediente 13627, sentencia de 11 de diciembre de 2003, consejero ponente Ricardo Hoyos-Duque. Disponible en: http://190.24.134.114:8080/WebRelatoria/ce/index.xhtml

Consejo de Estado, Sección Tercera, expediente 18273, sentencia de 29 de enero de 2004.

Consejo de Estado, Sección Tercera, expediente 14696, sentencia de 1 de julio de 2004. 
Consejo de Estado, Sección Tercera, expediente 14022, sentencia de 5 de mayo de 2005.

Consejo de Estado, Sección Tercera, expediente 15745, sentencia de 23 de noviembre de 2005, consejero ponente Ramiro Saavedra-Becerra. Disponible en: http://190.24.134.114:8080/WebRelatoria/ce/index.xhtml

Consejo de Estado, Sección Tercera, expediente 13558, sentencia de 12 de diciembre de 2005, consejero ponente Alier Eduardo Hernández-Enríquez. Disponible en: http://190.24.134.114:8080/WebRelatoria/ce/index.xhtml

Consejo de Estado, Sección Tercera, expediente 14251, sentencia de 6 de julio de 2005, consejero ponente Alier Eduardo Hernández-Enríquez. Disponible en: http:// consejo-estado.vlex.com.co/vid/-52529259

Consejo de Estado, Sección Tercera, expediente 13542, sentencia de 13 de julio de 2005.

Consejo de Estado, Sección Tercera, expediente 28448, sentencia de 31 de mayo de 2006.

Consejo de Estado, Sección Tercera, expediente 15772, sentencia de 31 de agosto de 2006.

Consejo de Estado, Sección Tercera, expediente 15283, sentencia de 31 de agosto de 2006, consejero ponente Mauricio Fajardo-Gómez. Disponible en: http://190.24.134.114:8080/WebRelatoria/ce/index.xhtml

Consejo de Estado, Sección Tercera, expediente 31975, sentencia de 27 de noviembre de 2006, consejero ponente Ramiro Saavedra-Becerra. Disponible en: http://190.24.134.114:8080/WebRelatoria/ce/index.xhtml

Consejo de Estado, Sección Tercera, expediente 15201, sentencia de 30 de noviembre de 2006, consejero ponente Alier Eduardo Hernández-Enríquez. Disponible en: http://190.24.134.114:8080/WebRelatoria/ce/index.xhtml

Consejo de Estado, Sección Tercera, expediente 25063, sentencia de 30 de noviembre de 2006.

Consejo de Estado, Sección Tercera, expediente 28238, sentencia de 5 de diciembre de 2006.

Consejo de Estado, Sección Tercera, expediente 16460, sentencia de 6 de junio de 2007.

Consejo de Estado, Sección Tercera, expediente 15459, sentencia de 29 de agosto de 2007.

Consejo de Estado, Sección Tercera, expediente 15382, sentencia de 19 de septiembre de 2007.

Consejo de Estado, Sección Tercera, expediente 16010, sentencia de 19 de septiembre de 2007.

Consejo de Estado, Sección Tercera, expediente 16894, sentencia de 4 de octubre de 2007.

Consejo de Estado, Sección Tercera, expediente 16058-21112, sentencia de 4 de octubre de 2007.

Consejo de Estado, Sección Tercera, expediente 15567, sentencia de 4 de diciembre de 2007.

Consejo de Estado, Sección Tercera, expediente 15563, sentencia de 20 de febrero de 2008, consejero ponente Ramiro Saavedra-Becerra. Disponible en: http://190.24.134.114:8080/WebRelatoria/ce/index.xhtml 
Consejo de Estado, Sección Tercera, expediente 16996, sentencia de 20 de febrero de 2008.

Consejo de Estado, Sección Tercera, expediente 17131, sentencia de 7 de mayo de 2008.

Consejo de Estado, Sección Tercera, expediente 16491, sentencia de 23 de abril de 2008.

Consejo de Estado, Sección Tercera, expediente 15296, sentencia de 5 de junio de 2008.

Consejo de Estado, Sección Tercera, expediente 17163, sentencia de 16 de julio de 2008.

Consejo de Estado, Sección Tercera, expediente 17206, sentencia de 30 de julio de 2008.

Consejo de Estado, Sección Tercera, expediente 16533, sentencia de 13 de agosto de 2008, consejero ponente Ruth Stella Correa-Palacio. Disponible en: http://190.24.134.114:8080/WebRelatoria/ce/index.xhtml

Consejo de Estado, Sección Tercera, expediente 17651, sentencia de 15 de octubre de 2008.

Consejo de Estado, Sección Tercera, expediente AG-2004-605, aclaración de voto de 15 octubre 2008 .

Consejo de Estado, Sección Tercera, expediente 16333, sentencia de 22 de julio de 2009, consejero ponente Enrique Gil-Botero. Disponible en: http://190.24.134.114:8080/ WebRelatoria/ce/index.xhtml

Consejo de Estado, Sección Tercera, sentencia de 27 de enero de 1994.

Consejo de Estado, Sección Tercera, sentencia de 13 de julio de 1995.

Corte Constitucional, sentencia C-486-93, 28 de octubre de 1993, magistrado ponente Eduardo Cifuentes-Muñoz. Disponible en: http://corteconstitucional.gov.co/ relatoria/1993/c-486-93.htm

Corte Constitucional, sentencia C-299-94, 30 de junio de 1994, magistrado ponente Antonio Barrera-Carbonell. Disponible en: http://www.corteconstitucional.gov. co/relatoria/1994/C-299-94.htm

Corte Constitucional, sentencia C-280-96, 25 de junio de 1996, magistrado ponente Alejandro Martínez-Caballero. Disponible en: http://www.corteconstitucional. gov.co/relatoria/1996/c-280-96.htm

Corte Constitucional, sentencia C-333-96, 1 de agosto de 1996, magistrado ponente Alejandro Martínez-Caballero. Disponible en: http://www.corteconstitucional. gov.co/relatoria/1996/c-333-96.htm

Corte Constitucional, sentencia C-563-98, 7 de octubre de 1998, magistrados ponentes Antonio Barrera-Carbonell y Carlos Gaviria-Díaz. Disponible en: http://www. corteconstitucional.gov.co/relatoria/1998/c-563-98.htm

Corte Constitucional, sentencia C-665-00, 8 de junio de 2000, magistrado ponente José Gregorio Hernández-Galindo. Disponible en: http://corteconstitucional.gov.co/ relatoria/2000/C-665-00.htm

Corte Constitucional, sentencia C-1062-00, 16 de agosto de 2000, magistrado ponente Álvaro Tafur-Galvis. Disponible en: http://www.corteconstitucional.gov.co/ relatoria/2000/c-1062-00.htm

Corte Constitucional, sentencia C-832-01, 8 de agosto de 2001, magistrado ponente Rodrigo Escobar-Gil. Disponible en: http://www.corteconstitucional.gov.co/ relatoria/2001/c-832-01.htm 
Corte Constitucional, sentencia C-840-01, 9 de agosto de 2001, magistrado ponente Jaime Araujo-Rentería. Disponible en: http://www.corteconstitucional.gov.co/ relatoria/2001/c-840-01.htm

Corte Constitucional, sentencia C-1149-01, 31 de octubre de 2001, magistrado ponente Jaime Araujo-Rentería. Disponible en: http://www.corteconstitucional.gov.co/ relatoria/2001/c-1149-01.htm

Corte Constitucional, sentencia C-233-02, 4 de abril de 2002, magistrado ponente Álvaro Tafur-Galvis. Disponible en: http://www.corteconstitucional.gov.co/ relatoria/2002/c-233-02.htm

Corte Constitucional, sentencia C-391-02, 22 de mayo de 2002, magistrado ponente Jaime Córdoba-Triviño. Disponible en: http://www.corteconstitucional.gov.co/ relatoria/2002/c-391-02.htm

Corte Constitucional, sentencia C-455-02, 12 de junio de 2002, magistrado ponente Marco Gerardo Monroy-Cabra. Disponible en: http://www.corteconstitucional. gov.co/relatoria/2002/c-455-02.htm

Corte Constitucional, sentencia C-484-02, 25 de junio de 2002, magistrado ponente Alfredo Beltrán-Sierra. Disponible en: http://www.corteconstitucional.gov.co/ relatoria/2002/c-484-02.htm

Corte Constitucional, sentencia C-559-02, 23 de julio de 2002, magistrado ponente Alfredo Beltrán-Sierra. Disponible en: http://www.corteconstitucional.gov.co/ relatoria/2002/C-559-02.htm

Corte Constitucional, sentencia C-619-02, 8 de agosto de 2002, magistrados ponentes Jaime Córdoba-Triviño y Rodrigo Escobar-Gil. Disponible en: http://www. corteconstitucional.gov.co/relatoria/2002/c-619-02.htm

Corte Constitucional, sentencia C-125-03, 18 de febrero de 2003, magistrado ponente Marco Gerardo Monroy-Cabra. Disponible en: http://www.corteconstitucional. gov.co/relatoria/2003/c-125-03.htm

Corte Constitucional, sentencia C-311-03, 22 de abril de 2003, magistrado ponente Eduardo Montealegre Lynett. Disponible en: http://www.corteconstitucional. gov.co/relatoria/2003/c-311-03.htm

Corte Constitucional, sentencia C-778-03, 11 de septiembre de 2003, magistrado ponente Jaime Araujo-Rentería. Disponible en: http://www.corteconstitucional.gov.co/ relatoria/2003/c-778-03.htm

Corte Constitucional, sentencia C-965-03, 21 de octubre de 2003, magistrado ponente Rodrigo Escobar-Gil. Disponible en: http://www.corteconstitucional.gov.co/ relatoria/2003/c-965-03.htm

Corte Constitucional, sentencia C-542-05, 24 de mayo de 2005, magistrado ponente Humberto Antonio Sierra-Porto. Disponible en: http://www.corteconstitucional. gov.co/relatoria/2005/c-542-05.htm

Corte Constitucional, sentencia C-1189-05, 22 de noviembre de 2005, magistrado ponente Humberto Antonio Sierra-Porto. Disponible en: http://www.corteconstitucional. gov.co/relatoria/2005/c-1189-05.htm 
Corte Constitucional, sentencia C-338-06, 3 de mayo de 2006, magistrado ponente Clara Inés Vargas-Hernández. Disponible en: http://www.corteconstitucional.gov.co/ relatoria/2006/c-338-06.htm

Corte Constitucional, sentencia C-720-06, 23 de agosto de 2006, magistrado ponente Clara Inés Vargas-Hernández. Disponible en: http://www.corteconstitucional. gov.co/relatoria/2006/c-720-06.htm

Corte Constitucional, sentencia C-722-07, 12 de septiembre de 2007, magistrado ponente Clara Inés Vargas-Hernández. Disponible en: http://www.corteconstitucional. gov.co/relatoria/2007/c-722-07.htm

Corte Constitucional, sentencia D-665-95.

Corte Constitucional, sentencia SU-846-00, 6 de julio de 2000, magistrado ponente Alfredo Beltrán-Sierra. Disponible en: http://corteconstitucional.gov.co/ relatoria/2000/SU846-00.htm

Corte Constitucional, sentencia T-002-92, 8 de mayo de 1992, magistrado ponente Alejandro Martínez-Caballero. Disponible en: http://corteconstitucional.gov. co/relatoria/1992/t-002-92.htm

Corte Constitucional, sentencia T-406-92, 5 de junio de 1992, magistrado ponente Ciro Angarita-Barón. Disponible en: http://corteconstitucional.gov.co/ relatoria/1992/t-406-92.htm

Corte Constitucional, sentencia T-005-95, 16 de enero de 1995, magistrado ponente Eduardo Cifuentes-Muñoz. Disponible en: http://corteconstitucional.gov.co/ relatoria/1995/t-005-95.htm

Corte Constitucional, sentencia T-219-95, 17 de mayo de 1995, magistrado ponente Eduardo Cifuentes-Muñoz. Disponible en: http://www.corteconstitucional.gov. co/relatoria/1995/t-219-95.htm

Corte Constitucional, sentencia T-746-05, 14 de julio de 2005, magistrado ponente Clara Inés Vargas-Hernández. Disponible en: http://www.corteconstitucional.gov.co/ relatoria/2005/t-746-05.htm

Corte Suprema de Justicia, Gaceta Judicial, tomo CXVI, sentencia de 31 de mayo de 1966.

Corte Suprema de Justicia, sentencia de 19 de agosto de 1935.

Corte Suprema de Justicia, sentencia de 6 de septiembre de 1935.

Corte Suprema de Justicia, sentencia de 19 de noviembre de 1936.

Corte Suprema de Justicia, sentencia de 6 de septiembre de 1940.

Corte Suprema de Justicia, Sala de Casación Civil, expediente 4978, sentencia de 5 de mayo de 1999, magistrado ponente Jorge Antonio Castillo-Rugeles. Disponible en: http://190.24.134.69/busquedadoc/FULLTEXT.ASPX

Corte Suprema de Justicia, Sala de Casación Civil, expediente 5617, sentencia de 20 de junio de 2000, magistrado ponente Manuel Ardila-Velásquez. Disponible en: http://190.24.134.69/Sentencias/Civil/2000/Dr.Manuel\%20Isidro\%20Ardila\%20 Vel\%C3\%A1squez/SENTENCIAS/S-074-2000\%20[5617].doc

Corte Suprema de Justicia, Sala de Casación Civil, expediente 6492, sentencia de 17 de agosto de 2001, magistrado ponente Jorge Santos-Ballesteros. Disponible en: http://www.notinet.com.co/pedidos/gasl.doc 
Corte Suprema de Justicia, Sala de Casación Civil, expediente 6975, sentencia de 5 de octubre de 2004, magistrado ponente Pedro Octavio Munar-Cadena. Disponible en: http://190.24.134.69/busquedadoc/FULLTEXT.ASPX

Corte Suprema de Justicia, Sala de Casación Civil y Agraria, expediente 1995-0170, sentencia de 5 de diciembre de 2005, magistrado ponente Edgardo VillamilPortilla. Disponible en: http://190.24.134.69/busquedadoc/FULLTEXT.ASPX

Corte Suprema de Justicia, Sala de Casación Civil, expediente 11001-3103-006-199709327-01, sentencia de 13 de mayo de 2008, magistrado ponente César Julio Valencia-Copete. Disponible en: http://alizee.uniandes.edu.co/ava/AVA_200610_ Derecho_Hipertexto/lib/exe/fetch.php?media=csj-cc-13-may-2008.pdf

Corte Suprema de Justicia, Sala de Casación Civil y Agraria, sentencia de 9 de julio de 1971.

Corte Suprema de Justicia, Sala de Negocios Generales, sentencia de 19 de noviembre de 1919.

Corte Suprema de Justicia, Sala de Negocios Generales, sentencia de 24 de junio de 1924.

Corte Suprema de Justicia, Sala de Negocios Generales, sentencia de 2 de febrero de 1932.

Tribunal Contencioso Administrativo de Antioquia, expediente 25878, sentencia de 3 de julio de 1992.

\section{Jurisprudencia internacional}

Consejo de Estado Francés, Sección del Contencioso, sentencia de 7 de diciembre de 2007 (lectura del 21 de diciembre de 2007), número 289328, demandado Centro Hospitalario de Vienne.

Corte de Casación Italiana, sentencia 2761 de 1990.

Corte de Casación Italiana, sentencia 11133 de 1990.

Corte de Casación Italiana, sentencia 1341 de 1991.

Corte de Casación Italiana, sentencia 7262 de 1991.

Corte de Casación Italiana, sentencia 9170 de 1994.

Tribunal Constitucional español, STC, sentencia 53 de 1985, 11 de abril de 1985. Disponible en: http://hj.tribunalconstitucional.es/HJ/es/Resolucion/Show/433

Tribunal Supremo español, STS, sentencia 836, 16 de diciembre de 1987. 
